УДК 338.45

DOI: 10.14451/1.176.56

\title{
НАПРАВЛЕНИЯ РАЗВИТИЯ ЛОГИСТИЧЕСКОЙ СИСТЕМЫ УПРАВЛЕНИЯ НА ПРОМЫШЛЕННЫХ ПРЕДПРИЯТИЯХ
}

\author{
(c) 2019 Макаренко Сергей Александрович \\ кандидат экономических наук, доцент кафедры «Экономика и организация» \\ Московский политехнический университет, Россия, Москва \\ E-mail: samprepod@mail.ru \\ ( 2019 Зотов Алексей Николаевич \\ кандидат экономических наук, доцент кафедры «Экономика и организация» \\ Московский политехнический университет, Россия, Москва \\ E-mail: agor80@yandex.ru
}

(c) 2019 Лебедев Александр Ларионович

кандидат технических наук, профессор, ректор

Международный экономико-гуманитарный институт, Россия, Москва

E-mail: a.lebedev@imegi.ru

\section{(c) 2019 Семикова Ольга Руслановна}

кандидат экономических наук, доцент, проректор по учебно-методической работе Международный экономико-гуманитарный институт, Россия, Москва

E-mail: semikova@imegi.ru

В статье рассмотрены современные проблемы и направления развития логистической системы управления на промышленных компаниях. В качестве основных мероприятий по совершенствованию управления материальными потоками в промышленных компаниях предложены разработка политики риск-менеджмента, автоматизация документооборота.

Ключевые слова: промышленность, управление, эффективность, управление материальными потоками, риск, логистика, автоматизация деятельности промышленной компании, логистическая система управления

В современных условиях каждое успешное промышленное предприятие формирует и развивает эффективную логистическую систему управления $[2,8,10]$, которая охватывает различные функциональные области хозяйственной, производственной и экономической деятельности организации. Современная система логистики включает [6, 7]: материально-техническое снабжение (процесс закупки сырья, основных и дополнительных материалов, комплектующих изделий, полуфабрикатов); складское хозяйство (его функционал заключается в организации приемки, контроле, складировании и отпуске материальных ресурсов клиентам); транспортное хозяйство (включает выбор оптимальных видов транспорта, доставку материальных ресурсов клиентам, эксплуатацию транспортных средств, разработку оптимальных маршрутов); управление запасами (процессы хранения материальных запасов, оптимизация объемов хранимых запасов, планирование уровня запа- сов); распределение материальных ресурсов по различным производственным подразделениям организации; производственную логистику (процессы движения материальных ресурсов, деталей, заготовок по определенным технологическим операциям процесса производства); сбыт (процессы организации и управления реализацией промежуточной или готовой продукции клиентам с использованием прямых или косвенных каналов распределения). Повышение конкурентоспособности промышленной компании во многом основано на эффективной логистической системе управления [5]. Все это обуславливает актуальность темы данной статьи.

В таблице 1 систематизированы основные проблемы, с которыми сталкиваются промышленные компании в сфере управления материальными потоками. С учетом информации таблицы 1 промышленные компании должны формировать и реализовывать стратегии своего развития. 
Таблица 1. Проблемы и основные способы их решения в сфере управления материальными потоками промышленных компаний

\begin{tabular}{|l|l|}
\hline \multicolumn{1}{|c|}{ Определение проблем } & \multicolumn{1}{|c|}{ Пути решения проблемных ситуаций } \\
\hline $\begin{array}{l}\text { Несогласованность и противоречивость действий } \\
\text { сотрудников компании из-за отсутстия единой } \\
\text { политики в сфере управления материальными пото- } \\
\text { ками. Непонимание персоналом организации целей, } \\
\text { желательных методов работы, правил и принципов } \\
\text { деятельности для обеспечения достижения целей в } \\
\text { указанной сфере. }\end{array}$ & $\begin{array}{l}\text { Разработка стратегии компании на 3 года, в которой } \\
\text { сфере управления материальными потоками. }\end{array}$ \\
\hline $\begin{array}{l}\text { Высокие риски, присущие деятельности компании в } \\
\text { сфере управления материальными потоками. }\end{array}$ & $\begin{array}{l}\text { Разработка политики риск-менеджмента, направ- } \\
\text { ленной на минимизацию присущих рисков в сфере } \\
\text { управления материальными потоками, а также выра- } \\
\text { ботка алгоритма по снижению рисков. }\end{array}$ \\
\hline $\begin{array}{l}\text { Неэффективное и трудозатратное управление доку- } \\
\text { ментационным сопровождением в сфере управления } \\
\text { материальными потоками. }\end{array}$ & $\begin{array}{l}\text { Применить автоматизацию процессов для управле- } \\
\text { ния материальными потоками [1]. }\end{array}$ \\
\hline
\end{tabular}

В качестве основных мероприятий по совершенствованию управления материальными потоками в промышленных компаниях считаем целесообразным реализацию мероприятий по двум основным направлениям:

- мероприятия по разработке политики риск-менеджмента, направленной на минимизацию присущих управлению материальными потоками рисков, а также разработка алгоритма по снижению рисков;

- мероприятия по совершенствованию процесса и сопроводительной документации операций в сфере управлению материальными потоками.

1. Мероприятия по разработке политики риск-менеджмента, направленной на минимизацию присущих управлению материальными потоками рисков, а также разработка алгоритма по снижению рисков.

В качестве основных стратегических мер по снижению влияния рисков на деятельность промышленных компаний в сфере их операций по управлению материальными потоками предлагаем следующие меры:

- привлекать к сотрудничеству организации с достаточным опытом ведения производственной деятельности;

- проводить тщательную разработку и подготовку документации по взаимодействию сторон, которые принимают непосредственное участие в процессе реализации деятельности, а также по взаимодействию с различными организациями [4, 9];

- повышение эффективности деятельности отдела логистики, реализация оптимальной логистической стратегии и проведение полного комплекса работ по улучшению логистических процессов;

- привлечение к реализации деятельности сотрудников с большим опытом, с заранее оговоренными сроками и проведенными заранее проверками на определение качественных показателей деятельности;

- создание механизмов стимулирования сотрудников, в том числе участие в результатах деятельности компании;

- постоянный мониторинг текущего законодательства, разработка методов быстрого реагирования

- четкая и грамотная формулировка учредительных документов компании;

- привлечение для оформления данных документов специалистов, которые имеют опыт в данной области, квалифицированных юристов и переводчиков.

Целесообразно проанализировать основные факторы внешней среды, которые также оказывают влияние на деятельность промышленных компаний и могут повышать существующие риски [3]. Предлагаем следующие предложения по учету каждого из факторов внешней среды:

- социальные факторы должны быть приняты во внимание при анализе эффективности взаимодействия промышленной компании со своими партнерами. Сотрудники промышленной компании должны обладать знаниями деловой культуры организаций-партнеров;

- экономические факторы необходимо контролировать с помощью создания оптимальной структуры системы управления материальными потоками промышленной компании для удержания клиентов и получения большего дохода; 
- демографические факторы необходимо контролировать с помощью применения стратегии в сфере управления материальными потоками в отношении конкретных характеристик населения;

- культурные факторы необходимо контролировать с помощью культурной ориентации стратегии компании;

- этнические факторы необходимо контролировать с помощью ознакомления сотрудников компании с этническими правилами и политикой своих клиентов, сотрудников, партнеров и т.д.;

- политические факторы необходимо контролировать с помощью постоянного анализа политических факторов тех стран, с компаниями которых она сотрудничает;

- правовые и юридические факторы необходимо контролировать с помощью постоянного проведения соответствия внутренних документов и политик компаниями требованиям законодательства;

- технологические факторы необходимо контролировать с помощью постоянного анализа актуальности используемых технологий и модернизировать их при необходимости;

- факторы конкуренции необходимо контролировать с помощью сопоставления своей продукции, процессов и услуг с аналогичными процессами, продукцией и услугами конкурентов.

Промышленные компании могут применять следующие мероприятия для минимизации существующих рисков.

Во-первых, необходимо постоянно искать новые рынки ресурсов. Например, целесообразно рассмотреть перспективы сотрудничества с компаниями Юго-Восточной Азии, рынок которых по объему сопоставим с европейским рынком.

Во-вторых, промышленной компании необходимо удерживать и привлекать ресурсы внутри российского рынка. Для этого привлекаются ресурсы логистических структурных подразделений компании и других ее подразделений, которые ответственны за разработку и продвижение продукции и услуг. В случаях нестабильности и рисков экономической системы промышленной компании следует развивать новые виды продукции.

B-третьих, деятельность промышленной компании может быть проанализирована по на- правлению изменения структуры продукции и партнеров. Это может быть осуществлено как с помощью ужесточения отбора партнеров и повышения требований к риск-менеджменту.

B-четвертых, промышленная компания может рассмотреть возможность повышения дохода, например, за счет комиссии, что позволит диверсифицировать доходы компании. Однако компании следует очень внимательно изучить данный вопрос, так как повышение комиссий за совершение ряда важных операций может повлечь достаточно серьезные недовольства со стороны клиентов компании и партнеров, что приведет к повышению ее репутационных рисков.

2. Мероприятия по совершенствованию процесса и сопроводительной документации операций в сфере управления материальными потоками промышленной компании.

Для того чтобы сотрудники промышленной компании, которые занимаются процессом управления материальными потоками, могли принимать эффективные управленческие решения, в их распоряжении должны быть необходимые ресурсы, одним из которых является такой важный ресурс как время. Руководству организации необходимо обеспечить наличие необходимого и достаточного количества времени для своих сотрудников, чтобы они могли принять наиболее верное решение в той или иной ситуации, проведя анализ необходимых данных и информации. Реализация решения по поиску необходимого времени является достаточно сложной, так как сотрудники промышленной компании обладают стандартным рабочим днем и списком обязанностей, которые трудно подвергнуть изменениям. Именно поэтому важным стратегическим шагом будет внедрение инновационных мероприятий по автоматизации и роботизации процессов компании по операциям, которые потенциально могут быть автоматизированы и роботизированы. Отметим, что именно роботизация способна стать важным шагом к повышению эффективности деятельности промышленной компании, позволив сократить расходы от $10 \%$ до $100 \%$ в тех областях деятельности, которые являются рутинными, повторяемыми, алгоритмизируемыми.

Отметим, что глобальным бизнес-трендом сейчас является активное использование цифровых технологий. В таблице 2 приведен потенциал автоматизации в разных странах и пример- 
Таблица 2. Прогноз автоматизации экономической деятельности [11]

\begin{tabular}{|l|c|c|}
\hline \multicolumn{1}{|c|}{ Страна } & Потенциал автоматизации (\%) & $\begin{array}{c}\text { Количество человек, которые будут } \\
\text { затронуты автоматизацией (млн. } \\
\text { человек) }\end{array}$ \\
\hline Япония & 56 & 35,6 \\
\hline Индия & 52 & 235,1 \\
\hline Китай & 51 & 395,3 \\
\hline Россия & 50 & 35,4 \\
\hline Франция & 43 & 20,7 \\
\hline Германия & 48 & 8,7 \\
\hline Испания & 48 & 11,9 \\
\hline Великобритания & 43 & 60,6 \\
\hline СшА & 46 & 11,8 \\
\hline Италия & 50 & 7,2 \\
\hline Канада & 47 & \\
\hline
\end{tabular}

ное количество граждан данных стран, которых затронет процесс автоматизации.

В том числе в данном исследовании [11] был проведен анализ ситуации в России в разрезе различных сфер деятельности. Отметим, что потенциал автоматизации в промышленности очень высок и составляет 54\%, при этом количество человек, которые будут затронуты автоматизацией в данной сфере, составит 6,5 миллионов человек.

Осуществление деятельности промышленной компании повлечет за собой обязательную оптимизацию бизнес-процессов организации, повышение эффективности деятельности всех структурных подразделений компании с одновременным соблюдением высокого качества. Как результат - произойдет внедрение новых цифровых технологий, которые повысят эффективность деятельности промышленной компании при стабильном составе сотрудников или даже при их сокращении. Подчеркнем, что потенциал автоматизации в сфере деятельности промышленной компании говорит о том, что автоматизация для компании - это необходимый шаг, который будет вести к развитию деятельности компании. При этом промышленная компания получит преимущество, так как сможет предоставить своевременный, надежный и удобный сервис-продукт, сохранив при этом операционную эффективность. Основной целью роботизации промышленной компании является оптимизация процессов по управлению материальными потоками, прежде всего, грузоперевозками, вывод на качественно новый уровень показателей эффективности и качества продукции.
Выделим следующие бизнес-процессы промышленной компании, которые могут быть частично или полностью роботизированы:

- расчет стоимости продукции в сфере операций по управлению материальными потоками;

- автоматическая рассылка информации о заказе продукции;

- учет продукции;

- учет налогов;

- отчетность в фонды и различные контрольные организации;

- анализ тенденций и бизнес-аналитика;

- управление файлами;

- заказы, счета, управление договорами;

- транспортная логистика и др.

В таблице 3 систематизированы основные риски развития логистического управления в промышленных компаниях.

Промышленной компании целесообразно принять следующие меры по снижению вышеперечисленных рисков - сформировать алгоритм развития системы управления рисками в логистической деятельности, который проводится в организации менеджером по логистике на ежеквартальной основе с привлечением директора компании, юриста, главного бухгалтера, состоящий из следующих этапов:

- анализ рисков в логистической деятельности компании;

- ранжирование рисков по уровню значимости;

- использование шкалы оценки рисков;

- выбор оптимальных инструментов для снижения рисков;

- внедрение и последующая корректировка системы рисков. 
Таблица 3. Основные риски, присутствующие на каждом этапе логистического управления в промышленной компании

\begin{tabular}{|l|l|}
\hline \multicolumn{1}{|c|}{ Процесс } & \multicolumn{1}{|c|}{ Основные риски } \\
\hline Закупочная логистика & $\begin{array}{l}\text { Срыв поставки продукции, нарушение сроков поставки, утрата или по- } \\
\text { вреждение продукции, повышение закупочных цен поставщиком, невы- } \\
\text { полнение условий договора, задержка продукции по вине третьих сторон } \\
\text { (государственные органы). }\end{array}$ \\
\hline Логистика запасов & $\begin{array}{l}\text { Риски, которые связаны с потерями хранимой продукции, с потенциаль- } \\
\text { ными ошибками в прогнозировании объемов по запасам продукции, сбои } \\
\text { в поставках продукции. }\end{array}$ \\
\hline Логистика складирования & $\begin{array}{l}\text { Риски превышения объема хранения продукции, ведущие за собой нару- } \\
\text { шение производстенного ритма компании; риски утраты (хищения) про- } \\
\text { дукции по различным причинам (пожары, стихийные бедствия, поломки } \\
\text { систем жизнеобеспечения и др.). }\end{array}$ \\
\hline Транспортная логистика & $\begin{array}{l}\text { Коммерческий риск, заключающийся в срыве поставок, увеличение } \\
\text { транспортных затрат, нарушении сроков поставки продукции, невыпол- } \\
\text { нении финансовых обязательств партнерами компании; риск ущерба в } \\
\text { результате воздействия погодных условий; риски утраты (хищения груза) } \\
\text { в процессе транспортировки. }\end{array}$ \\
\hline $\begin{array}{l}\text { Логистика производственных } \\
\text { процессов }\end{array}$ & $\begin{array}{l}\text { Риск нарушений производственных процессов, которые могут повлечь за } \\
\text { собой финансовые потери компании. }\end{array}$ \\
\hline $\begin{array}{l}\text { Сбытовая (распределительная) } \\
\text { логистика }\end{array}$ & $\begin{array}{l}\text { Риски, возникающие из-за неэффективной системы распределения и сбы- } \\
\text { та; риски утраты (хищения груза) в процессе сбыта. }\end{array}$ \\
\hline Информационная логистика & $\begin{array}{l}\text { Риск неисполнения мероприятий для развития интегрированной ин- } \\
\text { формационной системы компании и повышения уровня автоматизации } \\
\text { процессов. }\end{array}$ \\
\hline
\end{tabular}

Таким образом, в статье рассмотрены современные проблемы и направления развития логистической системы управления в промышленных компаниях. В качестве основных мероприятий по совершенствованию управления материальными потоками в промышленных компаниях предложены разработка политики риск-менеджмента, автоматизация документооборота и развитие системы мотивации сотрудников.

\section{Библиографический список}

1. Багаутдинова Д.з., Секерин Д.В. Внедрение системы автоматизации как фактор повышения эффективности на промышленном предприятии // Экономика и предпринимательство. 2015. № 6-1 (59-1). С. 580-582

2. Горохова А.Е. Факторы развития промышленных предприятий в условиях становления постиндустриальной экономики // Экономика и предпринимательство. - 2014. № 12 ч.2.- С. 870-873

3. Горохова А.Е., Нижегородцев Р.М., Секерин В.Д. Предпринимательство как фактор инновационного развития российской экономики // Вестник экономической интеграции. 2011. № 8. С. 44-48

4. Ефремов А.А. Лизинговые отношения в формировании цепей поставок // Проблемы современной экономики. 2011. № 1 (37). С. 145-148

5. Ефремов А.А. Логистическая стратегия развития сетевых структур лизинга // Известия Санкт-Петербургского университета экономики и финансов. 2012. № 1 (73). С. 68-74.

6. Логистика и управление цепями поставок /Букринская Э.М., Гвилия Н.А., Дмитриев А.В., Ефремов А.А., Килль М.Ю., Павлов М.Ю., Рудковский И. Ф., Смирнова Е.А.- Учебник / Москва, 2017.

7. Секерин В.Д., Петров С.Б. Современные подходы к контроллингу // Маркетинг. 2009. № 5. С. 24-32

8. Секерин В.Д. Логистика.- М.: КНОРУС, 2011

9. Секерин В.Д., Горохова А.Е. Новые технологии управления экономической деятельностью // Друкеровский вестник. 2018. № 4.- С. 32-37

10. Управление организацией: учебник / под ред. А.Г. Поршнева, 3.П. Румянцевой, И.А. Саломатина.- М.: ИНФPA-M, 2017.- 736 c.

11. World Economic Forum. (2018). The global risk report. Retrieved from http://www3.weforum.org/docs/WEF GRR18_Report.pdf 